\title{
The Singapore Paediatric Triage Scale Validation Study
}

\author{
Sashikumar Ganapathy ${ }^{1}$, MB BCh BAO, MRCPCH, Joo Guan ${\underline{Y e 0^{1}}}^{1}$ MBBS, MRCPCH, Xing Hui Michelle Thia ${ }^{1}$, BN, AdvDipNR, \\ Geok Mei Andrea $\underline{\mathrm{Hei}}^{1}$, BN, AdvDipNR, Lai Peng $\underline{\mathrm{Tham}}^{1}$, MBBS, MMed
}

INTRODUCTION This study aimed to determine the usefulness and validity of the triaging scale used in our emergency department (ED) by analysing its association with surrogate clinical outcome measures of severity consisting of hospitalisation rate, intensive care unit (ICU) admission, length of ED stay, predictive value for admission and length of hospitalisation.

METHODS A retrospective observational study was conducted of the performance markers of the Singapore Paediatric Triage Scale (SPTS) to identify children who needed immediate and greater care. All children triaged and attended to at the paediatric ED at KK Women's and Children's Hospital, Singapore, from 1 January 2014 to 31 December 2014 were included. Data was retrieved from the Online Paediatric Emergency Care system, which is used for patients' care from initial triaging to final disposition.

RESULTS Among 172,933 ED attendances, acuity levels 1, 2 plus, 2 and 3 were seen in 2.3\%, 26.4\%, 13.5\% and 57.8\% of patients, respectively. For admissions, triage acuity level 1 had a strong positive predictive value (79.5\%), while triage acuity level 3 had a strong negative predictive value (93.7\%). Fewer patients with triage acuity level $3(6.3 \%)$ were admitted as compared to those with triage acuity level $1(79.5 \%)(p<0.001)$. There was a correlation between triage level and length of ED stay.

CONCLUSION The SPTS is a valid tool for use in the paediatric emergency setting. This was supported by strong performance in important patient outcomes, such as admission to hospital, ICU admissions and length of ED stay.

Keywords: paediatric emergency medicine, paediatric triage, triage scale

\section{INTRODUCTION}

Triage is a systematic approach of prioritising patients' treatment based on the severity of their presenting condition. It also acts as a predictor for the nature and scope of care likely to be required. ${ }^{(1)}$ It is a crucial 'safety net' in a busy and often overcrowded emergency department (ED). An effective triage system allows critically ill patients in need of life-supporting treatment to be accurately identified. Correspondingly, it safely identifies less urgent patients who can wait in line for consultation. ${ }^{(2)}$ Finally, as with any robust clinical stratification tool, reproducibility is a key component of an effective triage system, whereby the allocation of triage level should be consistent among the various healthcare professionals working in the ED. ${ }^{(3)}$

Many different triage tools have been reported in the past. Among these, the Emergency Severity Index (ESI), Manchester Triage System (MTS), Australasian Triage Scale, and Canadian Emergency Department Triage and Acuity Scale are the most widely used..$^{(4-7)}$ The Singapore Paediatric Triage Scale (SPTS), currently used in our local tertiary paediatric hospital, is a fourlevel triage system. Patients are triaged by trained nurses based on three fundamental aspects: quick initial impression of illness severity using the Pediatric Assessment Triangle (PAT); historytaking and evaluation of the presenting complaint; and assessment of behaviour and age-related physiological measurements. The Severity Index Score (SIS) is incorporated into this assessment to determine the urgency of care. ${ }^{(8)}$ The SPTS was initiated in 1997 and has since been revised to the current version.
Although validated assessment tools have been incorporated into the local paediatric triage system, studies have shown a growing concern regarding the validity and reliability of triage scales. ${ }^{(9)}$ This is especially so for paediatric patients due to their limited ability to communicate their complaints. Consequently, nurses often have to rely on caregivers' perceptions when performing triage. This may result in an inaccurate assessment of the child's actual clinical status, as paediatric disease presentations often differ greatly from those of adult patients. ${ }^{(10)}$ Insufficient standardisation of triage scales and systems also leads to the use of paediatric scales with ambiguous validity. ${ }^{(11)}$

A valid and reliable triage system can help to improve ED operation and patient throughput. ${ }^{(12-14)}$ However, to our knowledge, the performance of the local triage system has not been formally assessed in a study. To address all these concerns, the present study was done to evaluate the performance of the triaging scale used in our ED by analysing its association with the following surrogate clinical outcome measures of severity: hospitalisation rate, intensive care unit (ICU) admission, length of ED stay, predictive value for admission and length of hospitalisation.

\section{METHODS}

This was a retrospective observational study in which all children who were triaged and attended to at the paediatric ED at KK Women's and Children's Hospital, Singapore, from 1 January 2014 to 31 December 2014 were included. The hospital's 
Table I. Triage criteria within the four categories of the Singapore Paediatric Triage Scale.

\begin{tabular}{|c|c|c|}
\hline Triage level/definition & Presentation & \\
\hline Category 1/Resuscitation (R) & $\begin{array}{l}\text { - Respiratory/cardiac arrest } \\
\text { - Grossly unstable vital signs/GCS } \\
\text { - Evidence of moderate-to-severe respiratory } \\
\text { distress } \\
\text { - Signs of hypoperfusion (shock) } \\
\text { - Sepsis syndrome }\end{array}$ & $\begin{array}{l}\text { - Severe dehydration } \\
\text { - Present seizure } \\
\text { - Altered mental state } \\
\text { - Febrile neutropenia (oncology patients } \\
\text { with fever) } \\
\text { - Major trauma } \\
\text { - Anaphylaxis }\end{array}$ \\
\hline Category 2 plus/Non-resuscitation (NR) & $\begin{array}{l}\text { - Mild-to-moderate respiratory distress } \\
\text { - Post-fit, conscious } \\
\text { - Stable poisonings } \\
\text { - Moderate-to-severe pain } \\
\text { - Moderation dehydration (vital signs stable) }\end{array}$ & $\begin{array}{l}\text { - Crush injuries } \\
\text { - Hyperpyrexia in children/neonatal pyrexia } \\
\text { - Deformed fracture/dislocated shoulder, } \\
\text { elbow, patella or ankle } \\
\text { - Burns/scalds } 5 \%-9 \% \\
\text { - Dislocated/dislodged permanent tooth }\end{array}$ \\
\hline Category 2/Non-resuscitation (NR) & $\begin{array}{l}\text { - Minor trauma requiring procedures } \\
\text { - All afebrile infants < } 3 \text { mth old } \\
\text { (not having any P1 or ' } 9 \text { ' case criteria) and } \\
\text { other indications }\end{array}$ & $\begin{array}{l}\text { - SIS } 8 \text { with acute complaints } \\
\text { (e.g. diarrhoea, abdominal pain with } \\
\text { stable vitals and reasonable hydration } \\
\text { status) }\end{array}$ \\
\hline Category 3/Emergency & $\begin{array}{l}\text { - SIS } 9 \text { and } 10 \text { with acute complaints (otherwise } \\
\text { stable vitals and normal activity level) }\end{array}$ & - Infants $<6$ mth old \\
\hline
\end{tabular}

GCS: Glasgow Coma Scale; SIS: Severity Index Score

paediatric ED is dedicated to handling patients aged below 16 years.

During the study period, all patients presenting to the ED were triaged by a registered nurse who was trained in the triage system. To perform triage, all nurses are required to: (a) have more than one year of working experience in the paediatric ED; (b) undergo a structured triage training programme for one month; (c) be satisfactorily evaluated by the nurse clinician and senior physicians in the department; and (d) complete a log of 200 supervised patient cases over a three-month period.

Upon the patient's presentation to the ED, the triage nurse first assessed his/her general appearance, work of breathing and circulation status using the PAT, a validated tool that facilitates rapid assessment of paediatric patients at all levels of illness and injury using visual and auditory cues. Studies have shown that the PAT is a reliable tool for the identification of critically ill children. ${ }^{(11)}$ Additionally, it has demonstrated high predictability of a child's clinical status upon further evaluation. ${ }^{(11)}$ Together with the assessment of triage complaint, vital signs and the SIS, ${ }^{(8)}$ patients were categorised into four acuity levels - Category 1 (Resuscitation), Category 2 plus and Category 2 (Non-resuscitation), and Category 3 (Less urgent, Emergency). Table I illustrates the four categories of the SPTS.

The performance of the triage system was evaluated based on its predictive value for admission, relationship with admission rate, level of hospitalisation care required, length of ED stay and length of hospitalisation. Data was retrieved retrospectively from the Online Paediatric Emergency Care system (Eutech Cybernectics, Singapore), which is used for patients' care from initial triaging to final disposition, including electronic prescription submission to the pharmacy. The data included age at presentation, gender, mode of arrival, reason for attendance (trauma or non-trauma), triage severity level (Category 1, Category 2 plus, Category 2 or Category 3), time and shift of arrival at the time of registration, and final disposition. The final disposition included discharge, admission (general care ward, high dependency [HD] ward or ICU), death on arrival and others (absconded and discharge against medical advice). Case definition for trauma included any head injuries from fall, vehicular accidents (including motor and nonmotor vehicles), assaults and burns. Hospital admissions (overall, ICU and HD ward) were used as the primary outcome measures. The secondary outcome measure was length of hospitalisation. The study was approved by the SingHealth Centralised Institutional Review Board, with waiver of informed consent.

All data was imported directly into an Excel 2010 spreadsheet (Microsoft, Richmond, WA, USA) and analysed with STATA software version 11.2 (StataCorp, College Station, TX, USA). All categorical data was described with counts and percentages. Skewed continuous data was described with medians and interquartile ranges (IQRs). Primary analysis of triage level and hospitalisation rate was done for all hospital and ICU admissions. The positive and negative predictive values for hospitalisations of the different triage acuity levels were calculated. Frequency histograms of length of hospitalisation were plotted for the different triage acuity levels. Correlation between triage level and dichotomous outcomes was evaluated using chi-square test. Non-parametric comparison of multiple groups was done with the Kruskal-Wallis test.

\section{RESULTS}

During the one-year study period, there were a total of 172,933 ED attendances. The baseline characteristics of the patients are presented in Table II. Median age was 3.3 (IQR 1.4-6.8) years and there was a slightly higher proportion of boys (55.9\%). The less urgent Category 3 patients accounted for a majority of the attendances $(57.8 \%)$, while the severe Category 1 patients consisted of only $2.3 \%$. Out of all the attendees, 28,559 (16.5\%) children were admitted for continual care.

Trauma-related patients made up $15.6 \%$ ( $n=26,894)$ of the attendances. Among the trauma patients, only a small number 
Table II. Baseline characteristics of patients $(n=172,933)$.

\begin{tabular}{|ll|}
\hline Variable & No. (\%) \\
\hline Age (yr)* & $3.3(1.4-6.8)$ \\
\hline Male gender & $96,668(55.9)$ \\
\hline Mode of transport (ambulance) & $3,368(1.9)$ \\
\hline Trauma & $26,894(15.6)$ \\
\hline Triage acuity level & \\
\hline Category 1 & $4,020(2.3)$ \\
\hline Category 2 plus & $45,725(26.4)$ \\
\hline Category 2 & $23,312(13.5)$ \\
\hline Category 3 & $99,876(57.8)$ \\
\hline Shift of arrival & \\
\hline Morning (08:00-16:00 hr) & $70,454(40.7)$ \\
\hline Evening (16:00-00:00 hr) & $75,952(43.9)$ \\
\hline Night (00:00-08:00 hr) & $26,527(15.3)$ \\
\hline Initial disposition & \\
\hline Discharged home & $142,647(82.5)$ \\
\hline Admitted (total) & $28,559(16.5)$ \\
\hline General ward & $27,741(97.1)$ \\
\hline High dependency ward & $656(2.3)$ \\
\hline Intensive care unit & $162(0.6)$ \\
\hline Other ${ }^{+}$ & $1,721(1.0)$ \\
\hline Death on arrival & $6(0.003)$ \\
\hline Data prented as meda (intera
\end{tabular}

${ }^{*}$ Data presented as median (interquartile range). +Includes absconded or discharge against medical advice.

$(\mathrm{n}=629,2.3 \%)$ were in Category 1 and another 5,220 were in Category 2 plus (19.4\%). On evaluating the performance of the triage system, for admissions, it was found that triage acuity level 1 had a strong positive predictive value of $79.5 \%$, while triage acuity level 3 had a strong negative predictive value of $93.7 \%$ (Table III). Only $6.3 \%$ of Category 3 patients were admitted as compared to $79.5 \%$ for Category 1 (chi-square test; $\mathrm{p}<0.001$ ).

The triage acuity level correlated well with the need for ICU admissions (Fig. 1), with 204 (5.1\%) patients triaged at triage acuity level 1 requiring ICU admissions overall. This was significantly lower for patients in the other triage categories. Of all the patients triaged at Category 3, only one was directly admitted to the ICU and seven were eventually transferred to the ICU after management in the wards, making it a total of $8(0.008 \%)$ patients triaged at Category 3 who required ICU admission. These eight patients are discussed in Table IV.

The triage acuity level also correlated well with the need for HD ward admissions, with $12.30 \%$ of patients triaged at triage acuity level 1 needing admission to the HD ward. Only $0.02 \%$ of all triage acuity level 3 patients required HD admission.

Although the triage acuity level predicted the need for hospitalisation, the median length of hospitalisation was similar across the different triage acuity levels. However, a statistically significant difference between the triage acuity level and length of hospitalisation was present, demonstrating at least a difference between two categories (Kruskal-Wallis test; $p<0.001$ ). Patients across all triage acuity levels had a median stay of 2 (IQR 1-3) days. Fig. 2 shows the frequency distribution of the length of hospitalisation for patients in the different triage acuity levels.

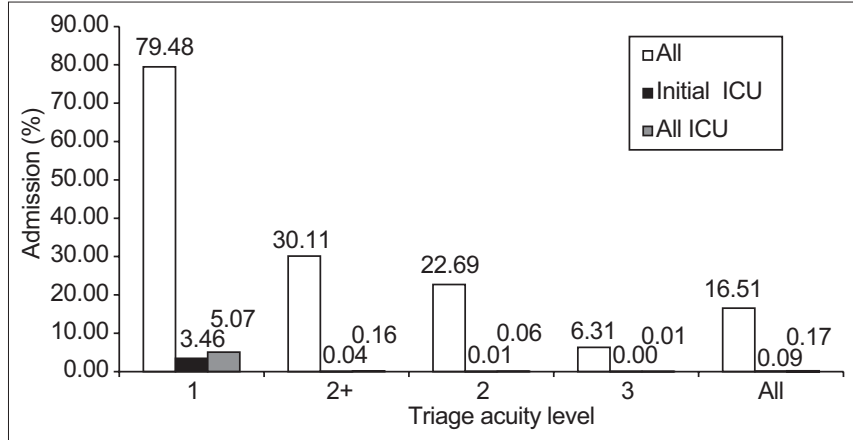

Fig. 1 Chart shows triage acuity level and intensive care unit (ICU) admission rates (initial and eventual).

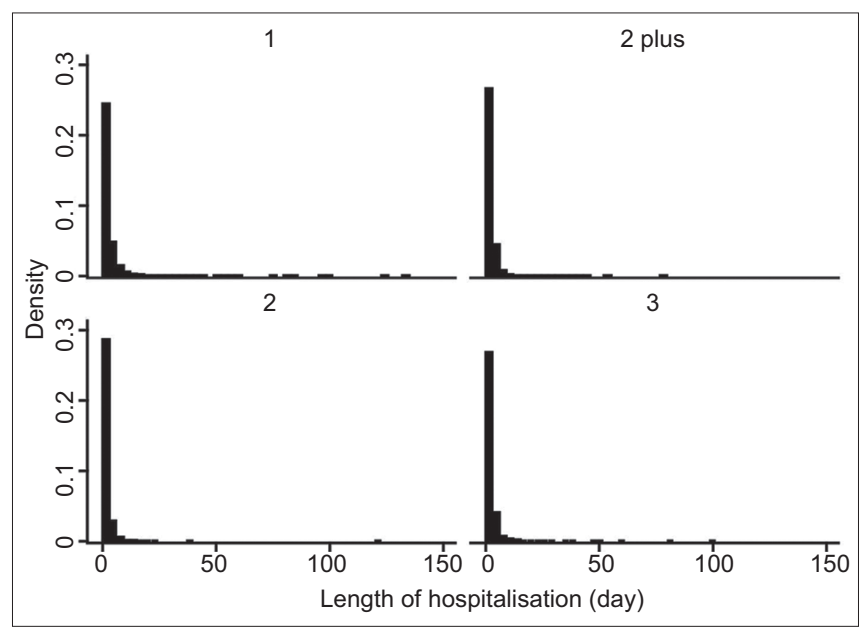

Fig. 2 Graphs show frequency distribution of the length of hospitalisation for triage acuity levels 1, 2 plus, 2 and 3. Note: median length of stay for the different triage levels was two days.

\section{DISCUSSION}

The present study shows that in our local population, the SPTS is strong in predicting the need for hospitalisation and ICU care. Triage acuity level 1 had a strong positive predictive value of $79.5 \%$ for all admissions and accounted for $85.8 \%$ of all initial ICU admissions. Conversely, the lowest acuity level of $3 \mathrm{had}$ a strong negative predictive value of $93.7 \%$. Only $0.008 \%$ of our Category 3 patients were admitted to the ICU. Our results are similar to a multicentre database study done in 12 Canadian paediatric EDs $-79 \%$ of patients who were triaged as resuscitation or emergent were admitted to the ICU and $0.9 \%$ of non-urgent cases were hospitalised, of which less than $0.01 \%$ were admitted to the ICU.(4) Our study contributes a different triage method comprising simple assessment tools that combine well to provide an effective triage scale.

The aim of triage is to identify patients who need to be seen urgently and our results supported the fact that critically ill paediatric patients were identified accurately at the initial presentation, where $97.5 \%$ of initial ICU admissions and $92.7 \%$ of all eventual ICU admissions were from Category 1 and Category 2 plus according to our triage system. This suggests that the triage system is safe in terms of the primary outcome of admissions (overall and ICU).

Other triage tools have demonstrated similar strong associations between triage levels and surrogate markers of 
Table III. Predictive values of triage acuity level on the need for hospitalisation.

\begin{tabular}{|c|c|c|c|c|}
\hline Triage acuity level & $\begin{array}{l}\text { Admitted* } \\
\text { ( } n=28,559)\end{array}$ & $\begin{array}{l}\text { Not admitted* } \\
(n=144,374)\end{array}$ & $\begin{array}{l}\text { Positive predictive } \\
\text { value }(\%)\end{array}$ & $\begin{array}{l}\text { Negative predictive } \\
\text { value }(\%)\end{array}$ \\
\hline Category 1 & 3,195 & 825 & 79.5 & 20.5 \\
\hline Category 2 & 5,289 & 18,023 & 22.7 & 77.3 \\
\hline Category 3 & 6,307 & 93,569 & 6.3 & 93.7 \\
\hline
\end{tabular}

*Data presented as number of patients.

Table IV. Details of patients, initially triaged at triage level Category 3 , who either required direct admission to the ICU or were subsequently transferred to it.

\begin{tabular}{|c|c|c|}
\hline Patient & Age (yr)/gender & Remarks \\
\hline 1 & 6/female & $\begin{array}{l}\text { Presented with intermittent headache and vomiting, with a normal physical examination at triage. Brain } \\
\text { CT showed right cerebellar mass with hydrocephalus and mass effect. She was transferred to CICU after } \\
\text { operation. }\end{array}$ \\
\hline 2 & $15 /$ male & $\begin{array}{l}\text { Presented with fever and headache. He had normal GCS and vital signs at triage. He was initially admitted } \\
\text { to the general ward, then transferred to HD ward } 24 \text { hours later and finally moved to the ICU due to } \\
\text { drowsiness and seizures. He was eventually diagnosed with autoimmune encephalitis. }\end{array}$ \\
\hline 4 & $7 /$ male & $\begin{array}{l}\text { Presented with fever and cough, and admitted for pneumonia. Later discovered to have congenital } \\
\text { diaphragmatic hernia. He was admitted to } \mathrm{CICU} \text { after operation. }\end{array}$ \\
\hline 5 & 16/female & $\begin{array}{l}\text { Presented with headache and vomiting. Neurological examination was normal at triage. She developed } \\
\text { unsteady gait in the ward and brain CT showed medulloblastoma. She was transferred to CICU after } \\
\text { operation. }\end{array}$ \\
\hline 7 & $10 /$ male & $\begin{array}{l}\text { Presented with vomiting and fever. He was diagnosed with diabetic ketoacidosis and started on } \\
\text { intravenous insulin. He was initially admitted to HD ward, and subsequently transferred to CICU for arterial } \\
\text { line insertion and monitoring. }\end{array}$ \\
\hline 8 & 10/male & $\begin{array}{l}\text { Presented with fever and cough for } 5 \text { days. Vital signs and examination were normal at triage. Full blood } \\
\text { count showed blasts with hyperleucocytosis. He was admitted to PICU for monitoring of tumour lysis } \\
\text { syndrome. }\end{array}$ \\
\hline
\end{tabular}

CICU: cardiac intensive care unit; CT: computed tomography; GCS: Glasgow Coma Scale; HD: high dependency; ICU: intensive care unit; PICU: paediatric intensive care unit

clinical severity in children. Baumann and Strout reported a high correlation between triage levels assigned using ESI and hospital admission rate, length of ED stay and resources used. ${ }^{(10)}$ Similarly, Roukema et al evaluated the ability of the MTS to identify true emergencies. ${ }^{(6)}$ Based on their sample of 1,065 patients, the authors found that the MTS had a sensitivity of $63 \%$ and specificity of $78 \%$ to identify true emergencies. ${ }^{(5,8)}$ Our initial disposition rate for patients during the study period was $82.5 \%$ discharged home and $16.5 \%$ hospitalised. Our discharge disposition rate was similar to the $85 \%$ discharge rate from a study conducted in 12 Canadian paediatric EDs. ${ }^{(4)}$

It is important that a triage scale is able to effectively detect the ill child from the well child. This will reduce the chance of prolonged waiting for a wrongly triaged child and delayed treatment for an emergency case. Systems that have a low predictor of admission or discharge and a large proportion of under-triage are unsafe. Overall, our results demonstrate that the SPTS used in our institution is strongly associated with the need for hospitalisation and admission to the cardiac intensive care unit, and also predicts discharge from the ED.

This study was not without limitations. This was a retrospective study and potential biases existed. Although its retrospective design reduced potential biases among the triage nurses and ED doctors who participated in the study (Hawthorne effect), the absence of physician blinding to the triage level may have influenced their decisions for admission. Also, although the results demonstrated a statistical difference between the different triage levels and the need for hospitalisation, the median length of hospitalisation was similar across all triage levels despite its statistical significance between groups. The validity of our triage system could be further evaluated by correlating the triage acuity level with ED and inpatient resource utilisations, which have previously been used in other studies as surrogate outcome measures for validity. ${ }^{(1,5,8,9)}$

There is no consensus on the gold standard for assessing triage systems. We based our assessment on previous published studies and derived our results from previously used acceptable standards. They mainly served as surrogate markers of triage validity. As with any robust clinical stratification tool, reproducibility is the key component of an effective triage system. ${ }^{(3)}$ In addition, the assessment tool must demonstrate invariable results on repeated measurements and reflect the genuine urgency that it is intended to measure. ${ }^{(5)}$ The inter- and intra-rater reliabilities could be tested to establish the reproducibility of our triage system. Finally, our 
study was done in a single centre, which may have limited the generalisability of the results. However, as KK Women's and Children's Hospital is the main children's hospital of Singapore, our cohort could be taken to represent the majority of the paediatric emergency visits in Singapore.

In conclusion, our results demonstrated that the SPTS is a valid tool for use in our paediatric emergency setting. This was supported by a strong performance in important patient outcomes, such as hospital admission, ICU admissions and length of ED stay. The validity of the SPTS would need to be further evaluated in multiple settings and populations to increase its validity and generalisability.

\section{REFERENCES}

1. Martins HM, Cuña LM, Freitas P. Is Manchester (MTS) more than a triage system? A study of its association with mortality and admission to a large Portuguese hospital. Emerg Med J 2009; 26:183-6.

2. Farrohknia N, Castrén M, Ehrenberg A, et al. Emergency department triage scales and their components: a systematic review of the scientific evidence. Scand J Trauma Resusc Emerg Med 2011; 19:42.

3. Bergeron S. Gouin S, Bailey B, Patel H. Comparison of triage assessments among pediatric registered nurses and pediatric emergency physicians. Acad Emerg
Med 2001; 9:1397-401

4. Gravel J, Fitzpatrick E, Gouin S, et al. Performance of the Canadian Triage and Acuity Scale for children: a multicenter database study. Ann Emerg Med 2013; 61:27-32.e3.

5. Gravel J, Manzano S, Arsenault M. Validity of the Canadian Paediatric Triage and Acuity Scale in a tertiary care hospital. CJEM 2009; 11:23-8.

6. Roukema J, Steyerberg EW, van Meurs A, et al. Validity of the Manchester Triage System in paediatric emergency care. Emerg Med J 2006; 23:906-10.

7. Green NA, Durani Y, Brecher D, et al. Emergency Severity Index version 4: a valid and reliable tool in pediatric emergency department triage. Pediatr Emerg Care 2012; 28:753-7.

8. Nelson KG. An index of severity for acute pediatric illness. Am J Public Health 1980; 70:804-7.

9. Chang YC, Ng CJ, Wu CT, et al. Effectiveness of a five-level Paediatric Triage System: an analysis of resource utilisation in the emergency department Taiwan. Emerg Med J 2013; 30:735-9.

10. Baumann MR, Strout TD. Evaluation of the Emergency Severity Index (version 3) triage algorithm in pediatric patients. Acad Emerg Med 2005; 12:219-24.

11. Horeczko T, Enriquez B, McGrath NE, Gausche-Hill M, Lewis RJ. The Pediatric Assessment Triangle: accuracy of its application by nurses in the triage of children. J Emerg Nurs 2013; 39:182-9.

12. Chen SS, Chen JC, Ng CJ, et al. Factors that influence the accuracy of triage nurses' judgement in emergency departments. Emerg Med J 2010; 27:451-5.

13. Fernandes $C M$, Tanabe $P$, Gilboy $N$, et al. Five-level triage: a report from the ACEP/ENA Five-level Triage Task Force. J Emerg Nurs 2005; 31:39-50.

14. van Veen $M$, Moll HA. Reliability and validity of triage systems in paediatric emergency care. Scand J Trauma Resusc Emerg Med 2009; 17:38. 